\title{
Health care costs of domestic violence against women - evidence from Portugal
}

\author{
Pedro Pita Barros \\ Universidade Nova de Lisboa
}

Eliana Barrenho

\author{
Manuel Lisboa \\ Universidade Nova de Lisboa \\ Dalila Cerejo \\ Universidade Nova de Lisboa
}

\begin{abstract}
:
Our main objective is to estimate the additional health care costs to the Portuguese National Health Service (NHS) due to domestic violence against women. We collected information through a survey addressed to health care centres' female users. Both victims and non-victims of violence were inquired. We estimate costs according to five different groups - consultation costs, health care treatment and therapeutic costs, costs of complementary and diagnostic exams, drugs costs and transport costs. The estimations have been split into two perspectives - the NHS perspective (public perspective) and private perspective of inquired women (out of pocket payments).

The timeframe of our calculations is one year, referring to all costs generated by domestic violence situations in the last twelve months. Essentially costs were estimated through the product of total number of episodes by the average estimated price per episode. Additionally, for the private costs, we also considered the costs originated by income losses, the opportunity cost of time spent on health care treatments and the work inability caused by sickness.

The results suggest that the victims of domestic violence's additional demand for health care is valued $€ 140$ per annum, that is about $22 \%$ higher than health care costs of non-victims. These results match those of similar studies for the United States, taking account of per capita differences in health care spending. A large proportion (90\%) of the additional costs associated with domestic violence is supported by the NHS, where consultations and drugs are the most important contributors of such costs. Health consequences of domestic violence result from losses in quality of life and worst health status of victims and correspond to additional permanent economic costs of domestic violence episodes.
\end{abstract}

Keywords: health care costs, domestic violence

JEL numbers: I18

\footnotetext{
* We benefited from a research grant awarded by the Portuguese Health Ministry, which is gratefully acknowledged. The usual disclaimer applies.
} 
2 of 27

Electronic copy available at: http://ssrn.com/abstract=1160306 


\section{Introduction}

Domestic violence is being recognized as an issue that cannot be ignored by society. Its costs, in several dimensions, have lead to a stream of studies and reports. These are mainly for the United States, but also in other countries evidence is gathered. For Portugal, we refer to Lisboa (2006), where evidence of social, psychological, health, education attainment and economic costs associated with domestic violence were assessed.

In this paper, we address a complementary issue: the health care costs associated with domestic violence against women. Following an episode of violence, women may go to the NHS for treatment of immediate problems. In addition, over time they may become more frequent users of the health care system. There are both short-term and long-term effects from domestic violence. We aim at their quantification in terms of monetary costs to both the National Health Service (NHS) and the women.

This study uses the information collected by Socinova in a survey addressed to primary care centre female users, which will be further described below.

The costs of domestic violence have been measured mainly with US data. Typically, such studies find evidence that women victims of domestic violence have health care costs higher than those that are not victims. Coker et al. (2004) estimate a difference of 1064 USD (about $760 €$ ) between victims and nonvictims of domestic violence, which is about $30 \%$ of annual health care costs of non-victims. An earlier study by Ulrich et al. (2003) reports an estimate of extra health care costs due to domestic violence in the range $60-130 \%$. Coker et al. (2004) reconcile their estimates with Ulrich et al. (2003) by stating that Ulrich et al. (2003) are mainly comparable with the probability of exceptionally high health expenditures.

The evidence for the US is reinforced by the recent estimates of Rivara et al. (2007), with an estimate of extra health care costs of domestic violence of about $19 \%$, corresponding to 439 USD (about $310 €$ ) per year.

From the economics literature, there is only a couple of studies devoted specifically to domestic violence. The ones closest to our objectives are due to Tauchen et al. (1991) and Bowlus and Seitz (2006). Both consider domestic violence as the outcome of family dynamics and negotiation. As explaining factors of domestic violence they include variables describing the nature of the relationship (age of spouses, existence of children, formal marriage), outside-marriage opportunities for each spouse (say, in terms of income earnings), preferences and the costs and probability of external intervention in the case of domestic violence. We do not have information allowing for a similar analysis. We concentrate our attention in the preliminary step of estimating the health care costs of domestic violence.

The paper is organized in the following way. Section 2 details the data gathering process, and how costs were computed from survey answers. Section 3 provides a descriptive view of the data and lays down the basic regularities. Section 4 presents our statistical analysis, disentangling immediate effects from long-run, 
health-mediated, effects of domestic violence episodes. The analysis provides an estimate of the average annual additional costs from domestic violence per victim. Finally, Section 5 discusses the main findings and concludes.

\section{The data}

To obtain an estimate of the health care costs of domestic violence against women, since no administrative data routinely collected is available a specific survey was launched, based on a previous survey. ${ }^{1}$ Data was collected in primary care centres, from 518 women. ${ }^{2}$ In most cases, between 30 and 40 interviews were carried out in each primary care centre. Of the 518 observations, 98 were a follow-up from a previous 2003 survey (out of the 420 women that answered the previous survey). Given the presence of some women that participated in the earlier survey on domestic violence (Lisboa, 2006), obtaining a random sample in the remaining observations was a concern in the design of the sampling. The fact that the survey was conducted at primary care centres may introduce a reporting bias, in the sense that women subject to domestic violence are more likely to be interviewed as they go more often to health care providers. For that motive, we do not make inferences about incidence or prevalence of domestic violence in the Portuguese population. Nonetheless, the survey provides detailed information regarding the use of health services, allowing the computation of differences across groups (victims and non-victims of violence).

In line with the survey addressed to primary care centres female users, five groups of costs were identified: consultations, medical treatments and therapies, complementary and diagnostic exams, drugs and transport costs. The costs have been divided into two categories - costs to the NHS and private costs to inquired women. Costs per woman surveyed are obtained multiplying the health care events performed by "their price". The events are for the past twelve months.

Additionally, for the private costs, we also considered type of costs originated by income losses, the opportunity costs of time spent in health care treatments and the work inability caused by sickness.

The health insurance's coverage has direct implications on the NHS expenditure, and on the private expenditure of the users. In particular, the additional coverage offered by insurance will facilitate the use of medical care, especially in the case of a woman victim of domestic violence.. Therefore, we identified the first choice of health care subsystem of inquired women. We found that, in the past twelve months, more than $89 \%$ of respondents are covered solely by the National Health Service, whereas additional $8.5 \%$ are covered by the main public health sub-system, ADSE. ${ }^{3}$ Because of their lack of representation in the

\footnotetext{
${ }^{1}$ See Lisboa (2006) on the previous survey. Our companion piece, Lisboa et al (2007) describes in further detail the main features of the design and answers of the survey.

${ }^{2}$ The primary care centres where data was collected were Castelo Branco, Covilhã, Penha de França, Alenquer, Loures/Mealhada, Amora, Feijó, Setúbal/Bonfim, Montemor-o-Novo, Alandroal, Viana do Alentejo, Serpa, Beja and Odemira.

${ }^{3}$ For a more detailed description of the Portuguese health system and the role of health subsystems, see Barros and Simões (2007).
} 
sample, other health sub-systems (SSMJ, ADMA, ADME, SAD / PSP, SAD / GNR, SAMS) were assumed to have a similar cost of the NHS.

\subsection{NHS expenditure}

In order to compute NHS costs, all health care acts occurred under NHS provision were ranked according to five cost groups, and were quantified according to the tables contained in Portaria No 110-A/2007 of 23 January, an upgrade of Portaria No 567/2006 of 12 June. $^{4}$

The NHS perspective was based on five different cost groups - consultations costs, health care treatment and therapeutic costs, costs of complementary and diagnostic exams, pharmaceutical costs and transport costs. Essentially costs resulted from the product of total health care episodes required per woman by the estimated price per episode.

These prices try to reflect an approximation of the real cost of the medical occurrence, including the workforce costs, and the costs of the procedures and auxiliary diagnosis and therapy performed in that episode.

Since NHS physicians often prescribe to their patients' health care acts supplied solely by private health providers, these consultations, therapies, treatments and diagnostic exams have a direct impact on the budget of the NHS. Therefore, the episodes performed by a private health subsystem prescribed by a NHS physician were also considered in the NHS expenditure. These occurrences costs were estimated by the cost episode considered by private health providers.

Estimating the value of each health care episode is a delicate problem. On one hand, the National Health Service institutions do not have detailed costing per episode, and their published prices comprise very rough calculations. On the other hand, what we really want is an estimate of the economic cost in terms of the resources allocated to the health care act. In many cases the published price might not be a realistic approximation to the underlying economic costs.

It is very important to decide about the reliability of the published prices and their economic suitability. Although most health care episodes were valued using the published prices, in some circumstances we opted to not follow literally those prices. On the whole, however, we conjecture these uncertainty cases do not influence significantly the studies' results.

\subsubsection{Consultations}

The NHS expenditure related to consultations was computed considering the product of the number of consultations by the cost per consultation. Consultation costs vary substantially according to the nature of the consultation (emergency, routine or specialty) and according to the level of hospital services (Central

\footnotetext{
${ }^{4}$ Portaria is a legal document, enacted by the Government, regarding day to day matters. They rank relatively low in the legal document hierarchy.
} 
hospital, District hospital, District level-one hospital or Primary Care Centre). This is the characterization suggested by the aforementioned diploma, therefore we followed it to estimate the consultation costs.

Because the costs of medical routine consultations do not depend on the type of hospital, we considered an equivalent cost to the external consultations, as stated in Portaria No. 110-A/2007, i.e., $€ 30$ per episode.

Costs related to specialist consultations were computed by the arithmetic average of medical specialist consultations costs and surgical specialist consultations costs, indicated by Instituto de Gestão da Informação Financeira da Saúde (IGIF - Institute for Financial Management and Informatics) in CUT (Total Unitary Cost) presented in the NHS Hospitals' Cost Accounting Report.

Total unitary cost represents full cost incurred in health care provision, including the costs of health care personnel, pharmacies, clinical consumables products, depreciation and other expenditures.

It was assumed that specialist consultation costs are independent of the hospital services categorization, i.e. costs per specialist consultation episode are identical in Central Hospitals, District hospitals, District Levelone hospitals and Primary Care Centres 5 .

There is evidence of differences between hospitals' CUT values and Primary Care Centres' CUT values. The dispersion of values within each group (Central hospitals, District hospitals, District Level-one hospitals and Primary Care Centres) is generally higher than the dispersion of the average values between groups.

Since there is no identification of the provider of each consultation and its CUT, we selected a common value, representing total costs associated to each consultation episode.

Regarding the presence of invalid answers about hospital specification demanded by inquired women, the provider that was geographically nearest to the user's residence was considered for the purpose of medical service characterization.

For the purposes of cost assessment, we considered higher-level public hospitals to have been used when responses stated more than one health care provider.

\footnotetext{
${ }^{5}$ This hypothesis does not have significant effect on results since average total cost with consultations, per person, drops from $€ 282.34$, considering the cost of $€ 134$ per specialist consultation in Primary Care Centre, for $€ 269$ assuming a cost of $30 €$ per specialist consultation episode (when held in a Primary Care Centre), given that there are only 15 cases of specialist consultations provided by Primary Care Centres.
} 
Table 1: Values for consultation costs

\begin{tabular}{|l|l|r|}
\hline Type of consultation & Health care provider & Cost per episode \\
\hline Emergency & Central hospital & $€ 143,5$ \\
\hline Emergency & District hospital & $€ 106$ \\
\hline Emergency & Level-one hospital & $€ 50$ \\
\hline Emergency & Primary Care Centre & $€ 35$ \\
\hline Control & Central hospital & $€ 30$ \\
\hline Control & District hospital & $€ 30$ \\
\hline Control & Level-one hospital & $€ 30$ \\
\hline Control & Primary Care Centre & $€ 134$ \\
\hline Speciality & Hospital & $€ 134$ \\
\hline Speciality & Primary Care Centre & \\
\hline Source:
\end{tabular}

Source: own computation, based on published NHS prices.

\subsubsection{Medical treatments and therapies}

To calculate the costs supported by the NHS, we took into account the number of sessions (frequency and duration) by type of treatment / therapy, and the average cost per group of treatment / therapy ${ }^{6}$.

Analysing previous surveys and the opinions of Directorate-General of Health (DGS) specialists, we identified the most predominant therapies and treatments. Seven types of therapies and treatments were considered (injections, adhesive bandage and treatments, small surgeries and scars treatment, fractures and ruptures treatment, dislocations and immobilization methods, physiotherapy treatments, psychiatric therapy and others).

Based on analysis of Governmental Regulation No. 567/2006 of 12 June (Appendix III) and Portaria No 110A/2007 of 23 January (Appendix III), the arithmetic averages for each therapy and treatment group was computed. The "Others" group corresponds to the average of other types of treatments and therapies not covered by the seven other categories.

However, information on the duration of treatment is still a problem, especially in the cases where we only know that the treatment had lasted for more than one month. In these events, and given the lack of detailed reporting, we assumed an average duration of six months.

\footnotetext{
${ }^{6}$ There is no accurate information about the average price of the psychiatric consultations held in private providers, so we opted to use a conservative price of $€ 50$ per psychiatric episode, in a treatment regime.
} 
Table 2: Estimated medical treatments and therapies costs

\begin{tabular}{|c|c|}
\hline Medical treatments and therapies group & Cost per episode \\
\hline Injections & $€ 4$ \\
\hline Adhesive bandage and treatments & $€ 14$ \\
\hline Small surgeries and scars treatment & $€ 45$ \\
\hline $\begin{array}{l}\text { Fractures and ruptures treatment, dislocations and } \\
\text { immobilization methods }\end{array}$ & $€ 46$ \\
\hline Physiotherapy treatments & $€ 11$ \\
\hline Psychiatric therapy & $€ 50$ \\
\hline Others & $€ 23$ \\
\hline
\end{tabular}

Source: Own computation, based on published NHS prices.

\subsubsection{Exams}

The costs supported by the National Health Service, similarly to the previous cost category, were estimated taking into consideration the number of examinations per inquired woman and the average cost per diagnostic exam category.

Nine types of complementary and diagnostic exams were considered (X-ray scan, Computed Tomography scan, Ultrasonography, Magnetic Resonance Imaging, Endoscopy, Laboratorial and complementary diagnosis, Mammography, Electrocardiogram and others), based on a selection of more frequent diagnostic exams, according to DGS experts and legal diplomas Portaria No. 110-A/2007 of January 23 and Portaria No. $567 / 2006$ of 12 June.

In the estimation of the average cost of each group of exams, to avoid an outliers effect, the exams presenting costs 4 to 5 times higher than the average for its exams group where not considered.

The price for the "Others" category corresponds to the arithmetic average of all other categories of diagnostic exams.

Table 3: Estimated complementary and diagnostic exams costs

\begin{tabular}{|l|r|}
\hline Complementary and diagnostic exams group & Cost per episode \\
\hline X-rays scan & $€ 25$ \\
\hline Computed Tomography scan & $€ 85$ \\
\hline Ultrasonography & $€ 34$ \\
\hline Magnetic Resonance Imaging & $€ 132$ \\
\hline Endoscopy & $€ 151$ \\
\hline Laboratorial and complementary diagnosis & $€ 39$ \\
\hline Mammography & $€ 66$ \\
\hline Electrocardiogram & $€ 87$ \\
\hline Others & $€ 77$ \\
\hline
\end{tabular}

Source: Own computation, based on NHS prices. 


\subsubsection{Pharmaceutical products}

To measure the costs of pharmaceutical drugs sustained by NHS, we assumed the monthly dosage basis, the duration of treatment (number of months) by drug and the average co-payment that NHS charges per pack.

With reference to the monthly dosage two types of monthly consumption of drugs were considered: an average consumption of one pack per month, applied to women that revealed they consumed daily/often/always those drugs, and an average consumption of 1/12 pack (or one package per year) for the women showing a temporary (acute condition) consumption behaviour (or did not indicate the quantity of such drugs consumed).

The calculation of average cost per pack charged to the NHS, was based on the reclassification of most drugs cited by surveyed women by mechanism of action, according to Infarmed (Therapeutic Drug and Statistics of 2004).

Because of lack of information about some pharmaceutical costs borne by the NHS, we used an estimated average cost through source of prescription, weighted by the number of packs sold in each of type of establishments (Infarmed, 2004).

On the other hand, we assumed a null cost to the NHS for drugs without pharmacologic information due to the high probability of them being non-reimbursed drugs.

\subsubsection{Patient transportations}

Transportation costs are paid by the patient except in the case of emergency care transportation, in which costs we considered subsidized. For the transportation provided by INEM (National Institute for Medical Emergencies), we considered a cost of $€ 0.37$ per km supported by the NHS, as presented in Governmental Regulation No. 726/2006.

To make use of the cost per km, we considered an average speed of $80 \mathrm{~km} / \mathrm{h}$ to estimate the travelled distance per trip, based on the time length of the journey, as revealed by the inquired women. ${ }^{7}$ To do this, we took into account the midpoint for the class intervals of time represented in the survey and a maximum of 120 minutes for the travelling duration.

\subsection{Private expenditure}

In addition to the five different cost groups already computed under the NHS perspective, we considered an indirect cost group related to income losses, the opportunity cost of time spent in health care treatments and the inability to work due by sickness.

\footnotetext{
${ }^{7}$ Assuming the same travelling time, if we consider a lower average speed applied to an urban travel, we can correlate, in a linear basis, the travelled distance and transport costs. Given their minor role involved, it wasn't considered a crucial issue for the analysis.
} 
Private costs vary substantially according to health insurance's coverage of inquired women. Therefore, in order to compute costs supported by inquired women, we also assumed the two most representative health care subsystems, in the past twelve months - National Health Service and the main public subsystem, ADSE. Because of their small numbers in the sample, other health subsystems (SSMJ, ADMA, ADME, SAD / PSP, SAD / GNR, SAMS) were assumed to have a similar cost of the NHS.

In order to compute private costs, all health care acts occurred under NHS provision were quantified according to co-payments per public health care act contained in Portaria No. 395-A/2007 of 30 March.

Regarding inquired women covered by ADSE, we took into account co-insurances set up in Regime Convencionado da ADSE (which describes the contracting of private sector providers to provide ADSE patients with specific health care services). To estimate the medical costs supported by ADSE users, we assumed co-insurance contract prices, and not the reimbursement provision scheme (fixed in Regime Livre da $A D S E$ ), because of the lack of information on private health care prices.

Since NHS physicians often prescribe their patients' health care acts that are supplied solely by private health providers, these have a direct impact on the budget of the NHS. Thus, the episodes prescribed by a NHS physician (such as therapies, treatments and diagnostic exams) performed by a private health subsystem were considered to have an effect in patients' expenditure similar to the co-payment ordered by NHS. ADSE patients pay a certain fixed amount per health care act, according to the contracting scheme of Regime Convencionado.

\subsubsection{Consultations}

Private consultation costs vary substantially according to the health care provider (whether it is public or private).

We assumed there were neither NHS reimbursements nor co-payments when calculating consultation costs provided by private health services providers to NHS patients. Therefore, consultation costs provided by private providers are assumed to be totally paid by NHS patients. On the other hand, we considered that only $20 \%$ of the consultation costs are charged to the ADSE patients (based on a Governmental Regulation No. $8738 / 2004-2^{\text {nd }}$ series). Given the lack of market information, we used an average cost of $€ 50$ per private consultation episode ${ }^{8}$.

Table 4: Assumed private consultation costs

\begin{tabular}{|l|l|}
\hline Subsystem & Cost per episode \\
\hline ADSE & $€ 29,55$ \\
\hline Others & $€ 50,00$ \\
\hline
\end{tabular}

\footnotetext{
${ }^{8}$ Assuming an average cost of $€ 80$ per private consultation episode, total average consultation cost increases from $€ 19$ to $€ 29$, and total consultation costs raises from $€ 9330$ to $€ 15210$. This hypothesis does not have significant effect on final results.
} 
Source: own computation, based on Governmental Regulation No. 8738/2004 - $2^{\text {nd }}$ series and assumption of market prices per private consultation episode.

The consultation costs of public health care provision are equal to the co-payments supported by patient. This fixed amount paid by patient differs according to the nature of the consultation (emergency or control) and according to the level of hospital services (Central hospital, District hospital or Primary Care Centre), as stated in Portaria No. 395-A/2007 of March 30.

At this point, there is a delicate methodological issue, associated to the exemptions from co-payments that include a considerable fraction of the population. User charges present a different cost sharing between NHS and patients. Given the fact that there isn't information about the respondent's exemptions, we considered that the inquired women do not benefit from any special co-payment exemption. We identified co-payment exemption for the two most significant benefiting groups (according to the description of conditions that exempt a citizen from co-payment integrated in Decreto-Lei (Decree-Law) N. ${ }^{\circ}$ 176/2003 of August 1): unemployed women (eligible only for subscribers of security and employment departments) and women earning less than national minimum monthly wage. Because of lack of information, we cannot identify user charges exemptions resulting from chronic diseases or other situations recognized by the aforementioned diploma (for instance, blood donors).

We assume that all respondents to whom these terms apply benefit from co-payment exemption, so they have no user charges for consultations, therapies, treatments and diagnostic exams. Considering this, average costs drastically drops from $€ 18,68$ to $€ 5,14$. NHS expenditure raises in the same magnitude.

Table 5: Co-payments per consultation episode

\begin{tabular}{|l|l|r|}
\hline Type of consultation & Health care provider & Cost per episode \\
\hline Emergency & Central hospital & $€ 8,75$ \\
\hline Emergency & District hospital & $€ 7,75$ \\
\hline Emergency & Level-one hospital & $€ 7,75$ \\
\hline Emergency & Primary Care Centre & $€ 3,40$ \\
\hline Control & Central hospital & $€ 4,30$ \\
\hline Control & District hospital & $€ 2,85$ \\
\hline Control & Level-one hospital & $€ 2,85$ \\
\hline Control & Primary Care Centre & $€ 2,10$ \\
\hline Speciality & Hospital & $€ 4,30$ \\
\hline Speciality & Primary Care Centre & $€ 2,10$ \\
\hline
\end{tabular}

Source: Own computation, based on NHS prices stated in Portaria No. 395-A/2007

The characterization suggested by the aforementioned diploma does not correspond to the classification stated in Portaria No. 110-A/2007 of March 23. Because of inexistence of Level-one hospital in the latter, it was considered the same co-payments charged to emergency and routine consultation episodes. 
Given the lack of information about co-payment charged for specialty consultation episodes, we opted to use a conservative price, corresponding to the highest fee (charged to Central Hospital health care episodes) charged for specialty consultation episodes provided by hospitals and primary care centres.

\subsubsection{Medical treatments and therapies}

We classified the most predominant therapies and treatments into seven types, as described above (injections, Adhesive bandage and treatments, small surgeries and scars treatment, fractures and ruptures treatment, dislocations and immobilization methods, physiotherapy treatments, psychiatric therapy and others). To calculate the costs supported by women, we used the average cost per group of treatment / therapy, which differs from NHS patients and ADSE patients. In case of patients covered by NHS, we used the values fixed by Portaria No. 395-A/2007 of March 30, and for ADSE patients used the "prices" established by Regime Convencionado da ADSE.

It was assumed an average cost per psychiatric episode of $€ 50$, and a reimbursement of $€ 20,45$ held by ADSE.

Table 6: Estimated medical treatments and therapies costs

\begin{tabular}{|c|c|c|}
\hline $\begin{array}{l}\text { Medical treatments and therapies } \\
\text { group }\end{array}$ & Health Care Provider & Cost per episode \\
\hline \multirow{2}{*}{ Injections } & ADSE & $€ 0,22$ \\
\hline & NHS and private providers & $€ 1,00$ \\
\hline \multirow{2}{*}{ Adhesive bandage and treatments } & ADSE & $€ 1,50$ \\
\hline & NHS and private providers & $€ 2,15$ \\
\hline \multirow{2}{*}{ Small surgeries and scars treatment } & ADSE & $€ 2,28$ \\
\hline & NHS and private providers & $€ 5,25$ \\
\hline \multirow{2}{*}{$\begin{array}{l}\text { Fractures and ruptures treatment, } \\
\text { dislocations and immobilization methods }\end{array}$} & ADSE & $€ 6,90$ \\
\hline & NHS and private providers & $€ 3,33$ \\
\hline \multirow{2}{*}{ Physiotherapy treatments } & ADSE & $€ 0,47$ \\
\hline & NHS and private providers & $€ 1,69$ \\
\hline \multirow{2}{*}{ Psychiatric therapy } & ADSE & $€ 0$ \\
\hline & NHS and private providers & $€ 29,55$ \\
\hline \multirow{2}{*}{ Others } & ADSE & $€ 6,82$ \\
\hline & NHS and private providers & $€ 2,24$ \\
\hline
\end{tabular}

Source: Own computations, based on NHS prices and Regime Convencionado - ADSE.

\subsubsection{Exams}

We estimated an average cost per diagnostic exam category, resulting from a characterization of nine types of complementary and diagnostic exams, based on a selection of more frequent diagnostic exams, 
according to DGS experts and legal diplomas Portaria No. 110-A/2007 of January 23 and Portaria No. $567 / 2006$ of 12 June?.

Table 7: Estimated complementary and diagnostic exams costs

\begin{tabular}{|c|c|c|}
\hline $\begin{array}{l}\text { Complementary and diagnostic exams } \\
\text { group }\end{array}$ & Health Care Provider & Cost per episode \\
\hline \multirow{2}{*}{$\mathrm{X}$-rays scan $\mathrm{s}$} & ADSE & $€ 4,24$ \\
\hline & NHS and private providers & $€ 1,93$ \\
\hline \multirow{2}{*}{ Computed Tomography scan } & ADSE & $€ 16,71$ \\
\hline & NHS and private providers & $€ 17,90$ \\
\hline \multirow{2}{*}{ Ultrasonography } & ADSE & $€ 6,96$ \\
\hline & NHS and private providers & $€ 4,82$ \\
\hline \multirow{2}{*}{ Magnetic Resonance Imaging } & ADSE & $€ 30,00$ \\
\hline & NHS and private providers & $€ 20,10$ \\
\hline \multirow{2}{*}{ Endoscopy } & ADSE & $€ 4,57$ \\
\hline & NHS and private providers & $€ 5,82$ \\
\hline \multirow{2}{*}{$\begin{array}{l}\text { Laboratorial and complementary } \\
\text { diagnosis }\end{array}$} & ADSE & $€ 4,62$ \\
\hline & NHS and private providers & $€ 4,24$ \\
\hline \multirow{2}{*}{ Mammography } & ADSE & $€ 6,35$ \\
\hline & NHS and private providers & $€ 5,25$ \\
\hline \multirow{2}{*}{ Electrocardiogram } & $\begin{array}{r}\text { ADSE } \\
\end{array}$ & $€ 4,78$ \\
\hline & NHS and private providers & $€ 4,64$ \\
\hline \multirow{2}{*}{ Others } & $\begin{aligned} \text { ADSE } \\
\end{aligned}$ & $€ 9,78$ \\
\hline & NHS and private providers & $€ 8,09$ \\
\hline
\end{tabular}

Source: Own computation, based on NHS prices and Regime Convencionado - ADSE.

\subsubsection{Pharmaceutical products}

The methodology used to measure the costs of pharmaceutical drugs sustained by inquired women is similar to the one assumed in NHS expenditure. Regarding private expenditure, the calculation of average total cost per pack (per mechanism of action) derives from the difference between medicine price and NHS co-insurance.

Because of lack of information about some medicine prices and costs supported by NHS, we used estimated the average course by source of prescription, weighting by the number of packs sold in each type of establishment (Infarmed, 2004).

\footnotetext{
${ }^{9} \mathrm{We}$ decided not using co-payment exemptions. If we considered free user chargers, this represents an enormous transfer costs to NHS. Average private costs would fall from $€ 12,59$ to $€ 3,88$. The categories with more evidence of these effect are Computed Tomography scan (from $€ 2,66$ to $€ 0,66$ ), Ultrasonography (from $€ 1,98$ to $€ 0,78$ ) and Laboratorial and complementary diagnosis (from $€ 4,27$ to $0,87)$.
} 


\subsubsection{Patients' transport costs}

We considered two types of costs to calculate transportation costs supported by women: monetary costs, spent on the trip to the health care centre as revealed by the respondents, and indirect costs, related to the opportunity costs of time spent on this trip.

Considering monetary costs, we took into account the midpoint for the class intervals of trip costs represented in the survey and a maximum of $€ 30$ per trip.

To quantify opportunity costs of time spent on transportation, we used the loss of earned income by inquired women.

\subsubsection{Indirect income losses}

Lost income corresponds to the opportunity cost of income losses related to work inability caused by sickness. We considered a loss of only $35 \%$ of monthly income to respondents that revealed that they had received a compensation for disease, based on compensation for disease rate of $65 \%$ stated by Ministry of Labour and Social Solidarity.

To calculate monthly income earned per inquired women, we computed the difference between total monthly household income and the sum of monthly individual income earned by contributors to household budget, appointed by respondents. After that, we identified some problems from disparities of inquired women responses, by the fact that some computed incomes resulted in negative incomes. We assumed zero income for incoherent answers to the survey. To calculate monthly income earned, we assumed a basis of 168 labour hours per month.

\section{Descriptive statistics}

For the data collected and for the valuations described in the previous section, we compute at the level of each respondent, basic descriptive statistics related to health care costs. Three groups of respondents are distinguished: non-victims of domestic violence, victims of domestic violence and victims of other types of violence. Classification into each group is based on the primary violence episode reported in the survey. In the reported cases of other types of violence, quite different situations exist, though the more frequent answers relate to the death of a family member or of a close friend.

The following table reports the average value of costs of health care, within each group, according to each type of health care costs. 
Table 8. Descriptive statistics

\begin{tabular}{|c|c|c|c|}
\hline & $\begin{array}{l}\text { Domestic } \\
\text { violence }\end{array}$ & Other violence & Non-victims \\
\hline Total costs & 826,52 & 856,15 & 640,51 \\
\hline Costs to women & 171,52 & 182,19 & 120,53 \\
\hline Consultation costs & 25,16 & 19,12 & 17,14 \\
\hline Costs of exams & 12,58 & 16,20 & 11,56 \\
\hline Costs of treatments & 5,40 & 1,82 & 1,85 \\
\hline Costs with drugs & 72,50 & 87,32 & 56,29 \\
\hline Private expenditures & 30,15 & 25,59 & 12,44 \\
\hline Transportation costs & 25,74 & 32,14 & 21,66 \\
\hline Costs to the NHS & 654,99 & 673,96 & 519,97 \\
\hline Consultation costs & 368,18 & 280,55 & 264,93 \\
\hline Costs of exams & 97,51 & 132,40 & 91,56 \\
\hline Costs of treatments & 44,63 & 21,08 & 14,61 \\
\hline Costs of drugs & 144,18 & 239,83 & 148,74 \\
\hline Transportation costs & 0,49 & 0,11 & 0,13 \\
\hline Absenteeism costs & 123,74 & 29,60 & 22,75 \\
\hline Number of observations & 68 & 128 & 322 \\
\hline
\end{tabular}

From this table, it is clear that victims of violence have higher health care costs, hinting that violence, either domestic or from some other source, determines higher use of the health care system. However, there is considerable dispersion associated with each average value. ${ }^{10}$ Therefore, we need to provide statistical sense to the apparent differences in average health care costs across the three groups. To this purpose, we present in table 9 the summary outcome of equality tests of average values, for each type of costs, of comparing each group against every other group. ${ }^{11}$

${ }^{10}$ The interested reader can confirm this claim by consulting the annex.

${ }^{11}$ The full information on tests can be found in the annex. 
Table 9. Summary of tests on equality of mean costs across groups

\begin{tabular}{|c|c|c|c|}
\hline & $\begin{array}{l}\text { Domestic } \\
\text { violence vs. non- } \\
\text { victims }\end{array}$ & $\begin{array}{l}\text { Domestic violence } \\
\text { vs. other type of } \\
\text { violence }\end{array}$ & $\begin{array}{llr}\text { Other type } & \text { of } \\
\text { violence } & \text { vs. non- } \\
\text { victim } & & \end{array}$ \\
\hline Total costs & $\checkmark$ & $\checkmark$ & $x$ \\
\hline Costs to women & $\checkmark$ & $\checkmark$ & $x$ \\
\hline Consultation costs & $\checkmark$ & $\checkmark$ & $\checkmark$ \\
\hline Costs of exams & $\checkmark$ & $\checkmark$ & $\checkmark$ \\
\hline Costs of treatments & $\checkmark$ & $\checkmark$ & $\checkmark$ \\
\hline Costs with drugs & $\checkmark$ & $\checkmark$ & $x$ \\
\hline Private expenditures & $\checkmark$ & $\checkmark$ & $\checkmark$ \\
\hline Transportation costs & $\checkmark$ & $\checkmark$ & $x$ \\
\hline Costs to the NHS & $\checkmark$ & $\checkmark$ & $x$ \\
\hline Consultation costs & $\checkmark$ & $\checkmark$ & $\checkmark$ \\
\hline Costs of exams & $\checkmark$ & $\checkmark$ & $\checkmark$ \\
\hline Costs of treatments & $\checkmark$ & $\checkmark$ & $\checkmark$ \\
\hline Costs of drugs & $\checkmark$ & $\checkmark$ & $x$ \\
\hline Transportation costs & $\checkmark$ & $\checkmark$ & $\checkmark$ \\
\hline Absenteeism costs & $\checkmark$ & $\checkmark$ & $\checkmark$ \\
\hline
\end{tabular}

Note: $\checkmark$ - means the null hypothesis of equal average costs across groups is not rejected; $x$ - means the null hypothesis of equal average costs across groups is rejected. All tests are performed under a $5 \%$ significance level.

From the set of equality tests, we observe the implications of the high variance in reported health care costs. In most cases, we cannot statistically reject the hypothesis of similar health care costs across groups. The only exceptions occur for the comparison of women victims of "other type of violence" versus "nonvictims of violence", where the former have higher costs associated with transportation and with pharmaceutical consumption.

The average cost analysis constitutes a first approximation to the issue of health care costs associated with violence, in particular, domestic violence. However, there is an important shortcoming of this analysis: we implicitly assume that women are randomly assigned to each group. An equivalent way to see it is to say that underlying characteristics of women across groups are, on average, similar. This may not be the case. For example, if older women use more often the health care system and there is a higher proportion of older women in the group of non-victims of violence, the difference between the two groups measured with no adjustment to age structure will be smaller than the difference after normalizing for the same age structure. The costs of domestic violence would be underestimated in this simple example. The next section addresses this concern.

\section{Regression analysis}

To cope with heterogeneity across groups, we use regression analysis to control for elements other than violence that may determine health care costs. As we have only categorical variables, transformed into sets of $0 / 1$ dummies, the analysis is basically a comparison by cells defined by the crossing of the different variables. A stepwise approach was used, by which, starting from the complete model, the variables that 
had a level of individual statistical significance below $10 \%$ were removed in sequence. In the next table, we denote the cases in which the dummy variables that identify "domestic violence" or "violence of other type" are statistically not different from zero by "-”.When those effects are statistically significant, the estimated coefficient is reported, providing a point estimate of the additional cost associated with the presence of violence, relative to the situation of non-violence. The corresponding $t$-statistic of the test of individual coefficient significance is also reported. The control variables for health care costs are age group, level of schooling achieved, income bracket and age group of the partner (whenever a partner exists).

A methodological note is in order here. Estimation of the relationship between costs (per type of health care cost) and its determinants has to be interpreted with caution. The finer the disaggregation by cost type, the more likely that a zero value is reported. Since the explanatory variables are $0 / 1$ variables, the estimated coefficients are, in reality, average values computed in each partition of the sample defined by the set of dummy variables. Due to this feature, we choose to keep the results of in-levels regressions rather than use other estimation techniques designed to address truncated dependent variables. ${ }^{12}$

It is often the case that health care costs have a highly skewed distribution, with a small proportion of cases having a high share of health care costs. A usual way of dealing with this issue consists in taking the log of cost values. This procedure was performed in our data. It produced results quite similar to the ones reported below. ${ }^{13}$ The estimation technique was OLS, using the stepwise approach to remove individually nonsignificant variables, as described above.

\footnotetext{
${ }^{12}$ For example, the tobit regression would be an alternative estimation technique.

${ }^{13}$ The application of the log transformation implied an asymmetry in the distribution that is now located at the left tail. Additionally, in the case of finer cost types, due to the existence of zero values, it is necessary to arbitrate whether it takes value zero or should it take the log of small some positive value. At this light, we choose to report in the main text the results based on level values, not log transformed values.
} 
Table 10. "Stepwise" regressions at $10 \%$ significance level, selected coefficients

\begin{tabular}{|l|l|l|l|}
\hline & $\begin{array}{l}\text { Domestic } \\
\text { violence }\end{array}$ & $\begin{array}{l}\text { Other type of } \\
\text { violence }\end{array}$ & $\mathbf{R}^{\mathbf{2}}$ \\
\hline Total costs & - & $210,55(2,01)$ & 0,0758 \\
\hline Costs to women & - & - & 0,0499 \\
\hline Consultation costs & - & - & 0,0367 \\
\hline Costs of exams & - & - & 0,0052 \\
\hline Costs of treatments & - & - & 0,0398 \\
\hline Costs with drugs & - & - & 0,0926 \\
\hline Private expenditures & $37,87(1,65)$ & - & 0,0682 \\
\hline Transportation costs & - & - & 0,0451 \\
\hline Costs to the NHS & - & $176,74(2,01)$ & 0,0863 \\
\hline Consultation costs & - & - & 0,0095 \\
\hline Costs of treatments & - & - & 0,0402 \\
\hline Costs of exams & - & - & 0,0090 \\
\hline Costs of drugs & - & $92,67(2,33)$ & 0,1058 \\
\hline Transportation costs & - & - & 0,0000 \\
\hline Absenteeism costs & - & - & 0,0091 \\
\hline Not Computation
\end{tabular}

Note: Computations used 324 observations, as for some of the variables there was not a valid answer.

Between parenthesis we report the $t$ statistic of individual significance.

Table 11. Regressions using specific sets of explanatory variables

\begin{tabular}{|l|r|r|r|r|}
\hline & \multicolumn{1}{|l|}{$\begin{array}{l}\text { Age variables } \\
\text { Domestic } \\
\text { violence }\end{array}$} & $\begin{array}{l}\text { Other type } \\
\text { of violence }\end{array}$ & $\begin{array}{l}\text { Domestic } \\
\text { violence }\end{array}$ & \multicolumn{1}{l|}{$\begin{array}{l}\text { Other type of } \\
\text { violence }\end{array}$} \\
\hline Total costs & 109,88 & $243,66^{*}$ & 117,29 & $194,06^{*}$ \\
\hline Costs to women & 45,91 & 67,01 & 35,92 & $57,96^{*}$ \\
\hline Consultation costs & 3,77 & 2,31 & 6,70 & 1,38 \\
\hline Costs of exams & 1,25 & 5,37 & 1,21 & 4,92 \\
\hline Costs of treatments & $-0,18$ & $-0,01$ & 3,69 & $-0,17$ \\
\hline Costs with drugs & 20,67 & $34,41^{*}$ & 0,96 & 28,10 \\
\hline Private expenditures & 15,82 & 13,56 & 19,78 & 13,15 \\
\hline Transportation costs & 4,59 & $11,37^{*}$ & 3,58 & $10,57^{*}$ \\
\hline Costs to the NHS & 63,97 & $176,66^{*}$ & 81,36 & 136,11 \\
\hline Consultation costs & 47,70 & 26,91 & 76,58 & 7,65 \\
\hline Costs of treatments & 5,44 & 6,58 & 30,90 & 5,90 \\
\hline Costs of exams & 6,40 & 43,45 & 2,86 & 38,77 \\
\hline Costs of drugs & 4,05 & $99,72^{*}$ & $-29,34$ & $83,82^{*}$ \\
\hline Transportation costs & 0,38 & $-0,02$ & 0,37 & $-0,03$ \\
\hline Absenteeism costs & 99,58 & 6,10 & 109,65 & 6,94 \\
\hline Number of observations & 503 & & 498 & \\
\hline Not
\end{tabular}

Note: * statistically significant at a $5 \%$ level.

The main regularity in the several variants of the model is the non-significance of estimated coefficients associated with health care costs of victims of domestic violence. Taken literally, this would be interpreted as stating that domestic violence does not imply additional health care costs, which is at odds with available international evidence.

Curiously, for Portugal, Carmo (2006, p.83) finds essentially the same empirical evidence in the use of health care (although data came from a different survey): "From a statistical point of view, we see that the 
probability of victims using [health care] is very similar to that of non-victims; therefore, it is not possible to establish a statistical relationship between the two phenomena."14

On the other hand, Vicente (2006, p. 97) using the same survey of Carmo (2006) concludes: ${ }^{15}$ "the impact of violence on the life of a person is not easy to qualify and quantify, given its wide range: emotional, behavioural, cognitive and physical. This being said, it will not be easy to estimate the associated costs." It is also stated that "health among women victims of violence is weak" (Vicente, 2006: p. 100).

This implies that the impact of domestic violence will persist over time, spanning several years and one of its consequences is a lower level of health to women victims of domestic violence. This characteristic suggests that the effect of domestic violence on health care can be mainly a mediated effect, through lower health status. In turn, the lower health status translates into a higher utilization of health care.

Taking this argument seriously leads to a two-step analysis: in the first step, one needs to establish whether there is, or not, an association between a woman being a victim of domestic violence and a lower health status (measured by self-assessed health). The second step consists in the unveiling, or not, of a relationship between a lower health status and a higher utilization of health care. The statistical analysis involved in these two steps cannot ignore that common factors may influence both health status and utilization of health care.

One strategy to identify effects will follow a recursive structure. In the first place, we assess whether, or not, the health status (self-perceived) is associated with the presence of domestic violence or other type of violence, on top of other aspects that may influence self-assessed health. These other aspects include age group, income level and schooling level. ${ }^{16}$

As self-assessed health is defined as a categorical variable with four classes (ranging from "bad" to “excellent"), an ordered probit model is used. The results are reported in Table 12.

\footnotetext{
${ }^{14}$ Own translation from the Portuguese original.

${ }^{15}$ Own translation.

${ }^{16}$ All these variables have empirical evidence supporting their role as determinants of health status. See Barros $(2003,2005)$ for evidence from Portuguese data.
} 
Table 12. Ordered probit, dependent variable: self-assessed health

\begin{tabular}{|l|r|r|}
\hline & Coefficient & \multicolumn{1}{|c|}{-statistic } \\
\hline Domestic violence & $-0,501$ & $-3,06^{*}$ \\
\hline Other type of violence & $-0,530$ & $-4,16^{*}$ \\
\hline Age: $25-34$ years old & $-0,515$ & $-1,98^{*}$ \\
\hline Age: $35-44$ years old & $-0,509$ & $-1,91^{* *}$ \\
\hline Age: $45-54$ years old & $-1,169$ & $-4,17^{*}$ \\
\hline Age: +55 years old & $-0,894$ & $-3,15^{*}$ \\
\hline Income: $501 €-805 €$ & 0,168 & 0,24 \\
\hline Income: $851 €-1500 €$ & 0,699 & $3,96^{*}$ \\
\hline Income: $1501 €-2750 €$ & 0,581 & $2,43^{*}$ \\
\hline Income: $2750 €-3750 €$ & 1,459 & $3,31^{*}$ \\
\hline Schooling 2 & 0,753 & $3,28^{*}$ \\
\hline Schooling 3 & 1,040 & $5,11^{*}$ \\
\hline Schooling 4 & 1,119 & $4,26^{*}$ \\
\hline Schooling 5 & 1,242 & $4,52^{*}$ \\
\hline Schooling 6 & 1,135 & $3,50^{*}$ \\
\hline Schooling 7 & 1,116 & $3,69^{*}$ \\
\hline Schooling 8 & 1,372 & $3,69^{*}$ \\
\hline Schooling 9 & 2,044 & $2,17^{*}$ \\
\hline Cut point 1 & $-1,924$ & $-2,58^{*}$ \\
\hline Cut point 2 & $-0,300$ & $-0,95$ \\
\hline Cut point 3 & 1,745 & 1,09 \\
\hline
\end{tabular}

Note: $*$ - statistically significant at $5 \% ; * *$ - statistically significant at $10 \%$.

The more relevant result is the negative impact of a violence episode, be it domestic violence or some other sort of violence, over the health status. On average, women victims of violence do report a lower health status, once differences in age, income and schooling level have been controlled for.

Additionally, the magnitudes of coefficients corroborate the usual evidence of higher income and higher schooling level being associated with a better health status. Naturally, older age is associated with a lower health status.

From this equation, we retrieve an estimate of the latent health status, $s_{i}$, where $i$ denotes each observation (woman) $i$, which we normalize to the interval $[0,1]$ according to

$h_{i}=\frac{s_{i}-s^{\min }}{s^{\max }-s^{\min }}$

where $s^{\min }$ denotes the minimum observed level, and $s^{\max }$ denotes the maximum observed value.

The estimated values for the latent health index have the following average values, reported in Table 13 . The estimated value for the health index will now be used as an additional regressor in the explanation of total health care costs (and of each cost type).

The health-mediated effect of domestic violence (or of other type of violence) will be present whenever the health status is affected by being a victim, on the one side, and in addition the health status does influence 
the use of health care. The two conditions must both hold for a health-mediated effect to be present (on top of the usual direct effect).

The ordered probit model is based on the concept of an underlying latent health index. This value of health is determined by several elements. We observe only a partition, corresponding to the categories of selfassessed health.

Let

$H_{i}^{*}=X_{i} \beta+\varepsilon_{i}$

be the latent index, where $X_{i}$ is a vector of variables containing the determinant factors of health, $\beta$ is a vector of parameters and $\varepsilon_{i}$ is a random term collecting all the non-specified elements.

The observed partition of self-assessed health is characterized by thresholds $\mu_{j}$ such that for $H_{i}^{*}>\mu_{1}$, the individual reports an "excellent" health status, for $\mu_{1} \geq H_{i}^{*}>\mu_{2}$ reports "good" and so on.

From this characterization, for each observation we can obtain the probability of obtaining an "excellent" health status:

$\operatorname{Pr}[$ "excellent" $]=\operatorname{Pr}\left[X_{i} \beta+\varepsilon_{i}>\mu_{3}\right]=1-\operatorname{Pr}\left[\varepsilon_{i} \leq \mu_{3}-X_{i} \beta\right]$

Assuming that $\varepsilon_{i}$ follows a Normal distribution, we can construct the probability of observing a response in each possible interval and the likelihood function for the data.

The combined effect, mediated by the health status, of a woman being a victim of domestic violence is obtained as

$\beta_{j} \times \alpha_{j} \times \frac{1}{s^{\max }-s^{\min }}$

where $\alpha_{j}$ is the impact of domestic violence in the health status, $\beta_{j}$ is the impact of health on health care costs, the last term in the expression being due to the normalization in the health status index. The effect will be statistically significant when all terms are statistically different from zero when evaluated individually.

A crucial element in the analysis is the definition of the set of explanatory variables in each phase. With respect to the self-assessed health, we consider: a) the age group of the woman, given the regularity usually found in the literature of lower health status for older people; b) schooling level, as a higher level of education allows for a better use of available resources and to achieve a better health status, ceteris paribus, and, c) income bracket.

To measure the (potentially) relevant effects of violence against women, divided into domestic violence and violence of other types, two dummy variables are included. 
Access to health care, on the other hand, can be easier if the woman benefits from supplementary coverage to the National Health Service, be it health subsystems (public or private) or voluntary health insurance. Therefore, we also include, in the regression, variables that identify any coverage on top of the National Health Service.

In the set of determinants of health care costs, we include the effect of extra coverage, the income bracket, the estimated self-assessed health, and markers for the status of the woman regarding violence (either domestic or from other type).

As standard in this sort of models, the inclusion of a constant term in the regression implies necessarily one omitted category for each dummy variable is required. The lower category in each variable was then omitted from estimation.

The full estimates produced can be found in the annex. In Table 15 we report only the coefficient for the variables addressing the presence of domestic violence and violence of other type, respectively. Estimates were computed for each line of costs.

Table 13. Health-mediated effects

\begin{tabular}{|l|r|r|r|}
\hline & Latent health index & Other type of violence & \multicolumn{2}{l|}{$\begin{array}{l}\text { Domestic } \\
\text { violence }\end{array}$} \\
\hline Total costs & $-1090,54^{*}$ & 82,26 & $-108,32$ \\
\hline Costs to women & $-140,42^{*}$ & $43,64^{*}$ & 12,59 \\
\hline Consultation costs & $-26,01^{*}$ & $-1,398$ & $-0,608$ \\
\hline Costs of exams & $-14,89$ & 3,347 & $-0,564$ \\
\hline Costs of treatments & $-2,47$ & $-0,74$ & $-0,43$ \\
\hline Costs with drugs & $-96,89^{*}$ & 15,993 & $-14,060$ \\
\hline Private expenditures & 22,73 & $16,846^{*}$ & $26,487^{*}$ \\
\hline Transportation costs & $-26,27$ & 8,668 & 1,407 \\
\hline Costs to the NHS & $-950,11^{*}$ & 41,62 & $-120,92$ \\
\hline Consultation costs & $-526,23^{*}$ & $-41,549$ & $-43,674$ \\
\hline Costs of treatments & $-11,91$ & 2,589 & 1,981 \\
\hline Costs of exams & $-122,22$ & 33,352 & $-8,435$ \\
\hline Costs of drugs & $-288,52^{*}$ & 47,378 & $-71,060$ \\
\hline Transportation costs & $-1,24^{*}$ & $-0,153$ & 0,273 \\
\hline Absenteeism costs & 31,10 & 7,067 & $116,38^{*}$ \\
\hline
\end{tabular}

Note: fixed effects to the neighbourhood were included, though not reported. Number of observations: 477 .

As a further robustness check on the results, two other proxies of the mediated impact of violence were also computed. The first takes advantage of a survey question about "having energy" ${ }^{17}$ The second question is about the "degree of satisfaction with life." 18

\footnotetext{
${ }^{17}$ It corresponds to the question "Currently, do you feel enough strength to do everything you find relevant?" in the survey.

${ }^{18}$ It corresponds to the question "Let me now ask you a more personal question: if you had to make a judgement on your life, how would you feel it?".
} 
Table 14. Effects on total costs

\begin{tabular}{|l|l|l|l|}
\hline & $\begin{array}{l}\text { "latent energy"/ } \\
\text { "latent satisfaction" }\end{array}$ & Other type of violence & Domestic violence \\
\hline $\begin{array}{l}\text { "satisfaction with life"- } \\
\text { mediated }\end{array}$ & $-2151,97 *$ & 152,50 & $-419,95$ \\
\hline "energy"-mediated & $-978,87 *$ & 149,49 & $-55,73$ \\
\hline
\end{tabular}

Nota: consideraram-se efeitos fixos ao nível da freguesia da inquirida; foram utilizadas 477 observações.

Table 15. Health costs estimates of violence

\begin{tabular}{|c|c|c|c|}
\hline & $\begin{array}{r}\text { Domestic } \\
\text { violence }\end{array}$ & $\begin{array}{c}\text { Violence of } \\
\text { other type }\end{array}$ & $\begin{array}{r}\text { Average value } \\
\text { non-victims }\end{array}$ \\
\hline Total costs & $146,02 €$ & $154,26 €$ & $640,51 €$ \\
\hline Costs to women & $18,80 €$ & $19,86 €$ & $120,53 €$ \\
\hline Consultation costs & $3,48 €$ & $3,68 €$ & $17,13 €$ \\
\hline Costs of exams & - & - & $11,16 €$ \\
\hline Costs of treatments & - & - & $1,85 €$ \\
\hline Costs with drugs & $12,97 €$ & $13,71 €$ & $56,29 €$ \\
\hline Private expenditures & - & - & $12,44 €$ \\
\hline Transportation costs & - & - & $21,66 €$ \\
\hline Costs to the NHS & $127,21 €$ & $134,39 €$ & $519,97 €$ \\
\hline Consultation costs & $70,46 €$ & $74,44 €$ & $264,93 €$ \\
\hline Costs of treatments & - & - & $14,61 €$ \\
\hline Costs of exams & - & - & $91,56 €$ \\
\hline Costs of drugs & $38,63 €$ & $40,81 €$ & $148,74 €$ \\
\hline Transportation costs & $0,17 €$ & $0,18 €$ & $0,13 €$ \\
\hline Absenteeism costs & - & - & $22,75 €$ \\
\hline
\end{tabular}

Overall, the results show that the direct effect of domestic violence on total cost of health care is not statistically different from zero, but the indirect, health-mediated, effect is about $146 € /$ year. The average health care expenditure of women that were victims of domestic violence is about $641 € /$ year (in our sample). That is, on average, the increase in health care costs associated with domestic violence is about $23 \%$ of "normal" health care costs.

The careful reader may feel the existence of a contradiction between the initial, reduced-form, estimates and the latest ones, with the health-mediated effect. The key feature to reconcile the two sets of estimates is to recognize the role of the two-step procedure associated with the indirect effect in smoothing out the impact on estimated values from outlier observations. 
To assess this explanation, we estimate the three main health care costs regressions using a robust technique that gives lower weight to extreme observations. ${ }^{19}$ Table 19 reports the estimates for the coefficients associated with domestic violence and with violence of other type. ${ }^{20}$ It can be easily confirmed the values are of the same order of magnitude of the two-step estimates, suggesting that these values are a better estimate than the simple reduced form estimates.

The values obtained, slightly above $20 \%$ of non-victims yearly health care costs, are in line with the US estimates of Cooker et al (2004) and Rivara et al (2007). Moreover, the number of observations in Coker et al. (2004) is half of the number of observations in this work. The statistical significance in the relationships estimated is of the same order of magnitude of those in Coker et al. (2004). As described above, Ulrich et al. (2003) report much higher estimates, which Coker et al. (2004) argue that they are due to the methodological approach. We can follow here a similar procedure. Define the level of health expenditure of a woman as exceptionally high when it exceeds the percentile $75 \%$. We find that the probability of a woman victim of domestic violence being above the $75^{\text {th }}$ percentile is 2,05 times higher compared to a nonvictim. ${ }^{21}$ Therefore, we find our results to be robust and broadly showing that also in Portugal domestic violence has significant additional health care costs. Given the organization of the health care system is based on a National Health Service, it comes as no surprise that the major share of the cost burden of domestic violence is actually borne by the NHS. The other main insight from our analysis is that long-term costs (in one-year period), namely health status deterioration, are more important than immediate costs.

\section{Final remarks}

The focus of the present work is to estimate the (extra) health care costs associated with situations of domestic violence against women. Our computations show an important indirect, health-mediated, effect, while direct effects show high variance due to extreme observations.

The central estimate points to an additional health care cost of $140 €$ per year per victim of domestic violence, roughly $22 \%$ of the average health care per year of non-victims of domestic violence (about $640 €$ / year). From these, $127 €$ (per year) are borne by the NHS, mainly in visits (to GP and/or to hospitals) $(55 \%)$ and in pharmaceutical products (30\%). The remaining $13 €$ are directly supported by women and $68 \%$ of it goes to pharmaceuticals.

\footnotetext{
${ }^{19}$ We choose to estimate with the robust technique only the regressions for total costs, NHS costs and total private costs, as the procedure of weighting extreme observations has a smaller effect when the dependent variable has a high proportion of zero values.

${ }^{20}$ The full set of estimated coefficients is available in the appendix.

${ }^{21}$ Obtained from a logistic regression, reported in the appendix.
} 
Of course, economic costs associated with violence against women go beyond the health care costs. One of the areas where long-term costs of domestic violence emerge is the labor market. These are addressed in Barros (2006) for the Portuguese market and are pursued further here. ${ }^{22}$

The value of $140 €$ per annum corresponds to $22 \%$ of total health care costs of women that have not been subject to violence (640€ per annum), a value that assessed in relative terms is aligned with the most recent estimates produced for the United States by Coker et al. (2004) and Rivara et al. (2007).

Although not being the main interest of this work, we also highlight that additional health care costs associated with other types of violence are significant and about the same order of magnitude of those of domestic violence. The situations included in "other type of violence" are associated with very different realities. Future research should address their role.

${ }^{22}$ In the international literature, the interested reader is referred to Swanberg and Logan (2005), Tolmand and Wang (2005) and Bowlus and Seitz (2006) for recent analysis. 


\section{References}

Barros, P.P., 2003, Estilos de vida e estado de saúde: uma estimativa da função produção de saúde, Revista Portuguesa de Saúde Pública, 3: 7-18. (Life-styles and health: an estimate of the health production function. In Portuguese)

Barros, P.P., 2005, Economia da Saúde - conceitos e comportamentos, Livraria Almedina. (Health Economics - concepts and behavior. In Portuguese)

Barros, P.P., 2006, Custos de longo prazo, in Manuel Lisboa, coordenador, Prevenir ou Remediar - os custos sociais e económicos da violência doméstica contra as mulheres, Lisboa, Edições Colibri/Socinova. (Long-term costs of domestic violence in Portugal. in Portuguese)

Barros, P. P. and J. A. Simões, 2007, Portugal: Health System Review, Health Systems in Transition, 9(5): $1-150$.

Bowlus, A.J. e S. Seitz, 2006, Domestic violence, employment and divorce, International Economic Review, 47(4): 1113-1149.

Carmo, I. do, 2006, Custos com a saúde física, in Manuel Lisboa, coordenador Prevenir ou Remediar - os custos sociais e económicos da violência doméstica contra as mulheres, Lisboa, Edições Colibri/Socinova, pp. 77-94. (Costs of physical health from domestic violence. In Portuguese).

Coker, A. L., C. E. Reeder, M. K. Fadden e P. H. Smith, 2004, Physical partner violence and Medicaid utilization and expenditures, Public Health Reports, Novembro - Dezembro, 119: 557-571.

Drummond, Michael F., O’ Brien, Bernard J., Stoddart, Greg L. and Torrance, George W., 1997, Methods for the Economic Evaluation of Health Care Programmes, Oxford, Oxford Medical Publications, pp. $217: 225$.

Farmer, A. e J. Tiefenthater, 1997, An economic analysis of domestic violence, review of Social Economy, 55(3): 337-358.

IGIF, 2005, Contabilidade Analítica dos Hospitais SNS, Lisboa, Institute for Financial Management and Informatics. (NHS Hospitals' Cost Accounting Report. In Portuguese)

IGIF, 2007, Relatório e Contas dos Hospitais SNS 2005, Lisboa, Institute for Financial Management and Informatics. (NHS Hospitals’ Financial Statements Report. In Portuguese)

INFARMED, 2004, Medicines Statistics, Lisbon, National Pharmacy and Health care Produtcs Authority. (www.infarmed.pt, accessed 25 May 2007).

INFARMED, 2007, Prontuário Terapêutico, Lisboa, Autoridade Nacional do Medicamento e Produtos de Saúde, I.P.. (www.infarmed.pt, accessed 28 May 2007).

Lisboa, M., 2006, editor, Prevenir ou Remediar - os custos sociais e económicos da violência doméstica contra as mulheres, Lisboa, Edições Colibri/Socinova. (Long-term costs of domestic violence in Portugal. in Portuguese)

Lisboa, M., P. Barros, D. Cerejo, E. Barrenho, A. Alfarroba, and J. Marteleira, 2007, Os custos económicos da prestação de cuidados de saúde às vitimas de violência, report delivered to the Ministry of Health (Portugal). (In Portuguese)

Rivara, F.P., M.L. Anderson, P. Fishman, A.E. Bonomi, R.J. Reid, D. Carrel e R.S. Thompson, 2007, Health care utilization and costs for women with a history of intimate partner violence, American Journal of Preventive Medicine, 32(2): 89-96.

Tauchen, H.V., A.D. Witte e S.K. Long, 1991, Domestic violence and employment: a qualitative study, Journal of Occupational Health Psychology, 10(1): 3-17. 
Tolman, R.M. e H.C. Wang, 2005, Domestic violence and women's employment; fixed effects models of three waves of women's employment study data, American Journal of Community Psychology, 36(1-2): 147-158.

Ulrich, Y.C., K.C. Cain, N.K. Sugg, F.P. Rivara, D.M. Rubanowice e R.S. Thompson, 2003, Medical care utilization patterns in women with diagnosed domestic violence, American Journal of Preventive Medicine, 24: 9-15.

Vicente, L.B., 2006, Custos psicológicos nas mulheres vítimas de violência doméstica, in Manuel Lisboa, coordenador, Prevenir ou Remediar - os custos sociais e económicos da violência doméstica contra as mulheres, Lisboa, Edições Colibri/Socinova, pp. 95-109. (Psychological costs in women victims of domestic violence. In Portuguese).

Ministério das Finanças e da Administração Pública, 2006, Relatório de Actividades da ADSE 2006, Lisboa, Direcção Geral da Protecção Social aos Funcionários e Agentes da Administração Pública, Ministério das Finanças e Administração Pública. (Activity Report of ADSE, Ministry of Finance and Public Administration).

Ministério das Finanças e da Administração Pública, Tabela de Comparticipações de Cuidados de Saúde do Regime Convencionado, Lisboa, Direcção Geral da Protecção Social aos Funcionários e Agentes da Administração Pública, Ministério das Finanças e Administração Pública. (www.adse.pt accessed in 15 June 2007, ADSE contracting scheme of private sector providers. In Portuguese).

Ministério das Finanças e da Administração Pública, Tabelas de Comparticipação do Regime Livre, Lisboa, Direcção Geral da Proteç̧ão Social aos Funcionários e Agentes da Administração Pública, Ministério das Finanças e Administração Pública. (www.adse.pt accessed in 15 June 2007, ADSE reimbursement provision scheme. In Portuguese).

\section{Relevant legislation}

Decree-Law No. 48/1990 of 24 August on the Fundamental Principles of Health, with changes introduced by Decree-Law No. 27/2002 of 8 November.

Decree-Law No. 28/2004 of 4 February and Decree-Law No 146/2005 of 26 August establishing compensation for disease by Ministry of Labour and Social Solidarity.

Decree-Law No. 201/2007 of 24 May establishing co-payment exemptions to victims of domestic violence.

Decree-Law No. 173/2003 of 1 August 1990 on the NHS co-payment exemptions.

Governmental Regulation No. 726/2006 of 26 April ( $2^{\text {nd }}$ series) establishing transportation costs charged by NHS.

Governmental Regulation No. 8738/2004 of 3 May ( $2^{\text {nd }}$ series) fixing Regime Convencionado da ADSE.

Portaria No 110-A/2007 of 23 January, changing Portaria No 567/2006 of 12 June defining prices for health care delivery in the National Health System.

Portaria No. 395-A/2007 of 30 March defining co-payments supported by NHS patients. 